\title{
Towards a post-consumer subjectivity: a future for the crafts in the twenty first century?
}

\author{
By Peter Hughes
}

A shorter version of this paper was presented at the international conference Making Futures: the Crafts in the Context of Emerging Global Sustainability Agendas at the Plymouth College of Art and Design, UK, September 2009 and published on the conference website at http://makingfutures. plymouth.ac.uk/journalvol1/papers.php\#critical-perspectives.

Peter Hughes has been Curator of Decorative Arts, Tasmanian Museum and Art Gallery since 1999. He received a Bachelor of Education (Art) from the City Art Institute (now COFA/UNSW) in 1986 and subsequently studied furniture design (Centre for the Arts, University of Tasmania). In 1995 he received a Master of Art (Research) in Art Theory from the Canberra School of Art, Australian National University for a thesis interpreting John Ruskin's writing about design, society and the natural world from a unifying ecological perspective. Peter continues to be interested in links between ecological philosophy, our relationship with 'objects' generally and the crafts as a political and social as well as artistic field of practice.

Abstract: The crafts movement has a long history of engagement with both environmental and ethical issues. In recent years, several movements have emerged-in response to environmental issues and in opposition to the dominance of the monoculture produced by globalising capitalismthat have powerful resonances with some of the crafts movement's early political and ethical heritage. As environmental issues move into the mainstream, a rising tide of concern presents an opportunity for the crafts movement to renew its engagement with social, political and philosophical issues and to contribute both to the debate and to the formation of a sustainable material and creative culture of the future.

\section{Paper}

Unfashionable though it may seem in an age of the always new yet instantly redundant, I would like to suggest that an idea about the relevance of crafts to the environmental challenges we face can be found by looking to the past. Looking, more specifically, to the intellectual legacy of the nineteenth century. Considering the birth of the contemporary studio crafts as a political and social movement rather than a merely artistic one, reveals a depth of what shall be referred to below as 'ecological understanding' that goes far beyond an awareness of environmental issues at the important, though often superficial level of nature preservation. After a brief account of the precarious position 
of the contemporary crafts and of our contemporary ecological situation, this paper will examine the relevance of philosophies influential in the formation of the Crafts Movement in the nineteenth and early twentieth centuries.

In recent years, the Crafts have been engaged in an increasingly desperate struggle to remain relevant in a hyper-industrialised world. Over the last three decades the two dominant alternatives to oblivion seem to have entailed either absorption into the field of design or into that of the 'fine arts'. The three areas of practice, craft, art and design, share many concerns and should be considered overlapping fields within visual culture that nonetheless have distinct identities. The design profession separates the act of design from that of making, which is usually done in factories by people who have no, or minimal, input into the design of the objects they produce. Art has been increasingly conceptually driven for well over two centuries, during which it has been progressively divested of its associations with craft, with particular materials and their skilful manipulation. This shared valorisation of the intellectual over the material is perhaps the underlying reason for the twenty first century marriage of art and design recently described by Deyan Sudjic, the Director of the Design Museum in London (2008, pp. 167-216). The key to craft, however, is the fusion of design and making and the ongoing dialogue this establishes between maker, object, materials and processes. By collapsing, to greater or lesser degrees, the distinction between the mind and the body, object and subject and, ultimately, the material and spiritual, craft represents a challenge to the dominant conceptual framework of our civilisation.

Craft with a capital ' $C$ ' is an epiphenomenon of modernity. Its catalyst was the industrial revolution of the nineteenth century and its subsequent social upheavals. While the crafts movement that arose in the last half of the nineteenth century was in part dedicated to the preservation of skills and traditions that were considered endangered, it was also and above all else, concerned with both individual creative expression and the nature of work and its relation to life more broadly. In this it should not be considered a continuation of traditional production, nor simply a romantic dream of returning to a previous state of social organization such as that which prevailed in the Middle Ages and had produced Gothic architecture, the idea of which was so important in the movement's genesis.

The Arts and Crafts Movement arose during an epochal change in the human condition brought about by the deployment of the steam engine powered by fossil fuels. This was the first advance in the technology of motive power since the domestication of animals and the exploitation of wind and water power for that purpose. Understandably, the steam engine and the technologies that followed hard on its heels gave rise to dreams of unlimited human progress through power over nature. It also gave rise to an exponential increase in the exploitation of natural resources and of the production of an ever-expanding volume and variety of commodities. As is well known, the first phase of industrialisation caused widespread social upheaval, exacerbated by rapid, unplanned urbanisation and environmental deterioration. This maelstrom of destruction and creative potential was the ground for the emergence of the Arts and Crafts and it is no accident that the question of how we-collectively and individually - are to live was then a central preoccupation. 

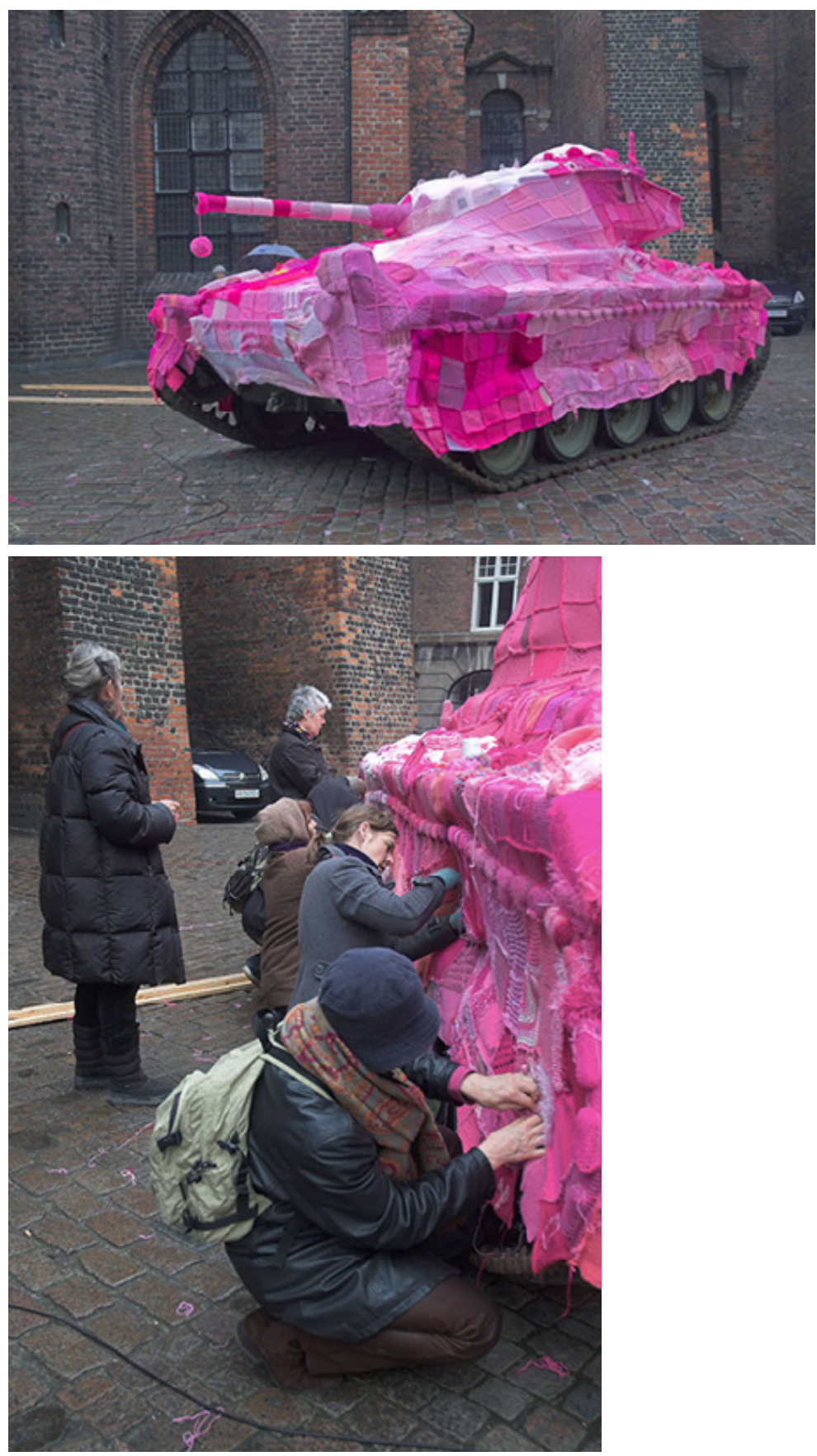

Plates 1 and 2: 'Craftivism' in action: Marianne Joergensen's Pink M.24 Chaffee is a collaborative project incorporating knitted squares from hundreds of contributors. As a protest against the Danish (and the American and British) involvement in the war in Iraq, a World War II tank was covered from canon to caterpillar tracks with squares of knitted and crocheted pink yarn. The $15 \times 15 \mathrm{~cm}$ squares were knitted by people from many European countries and the USA. The process of covering the tank was documented in a video shown at the Nikolaj, Copenhagen Contemporary Art Center, Denmark as part of the exhibition "TIME" from April 27 to June 42006. 
For three decades we have been experiencing a subsequent technological revolution on a scale commensurate with that of the nineteenth century. Digital technologies have not only changed the way we communicate with one another and provided a myriad of new toys, they also have a propensity to constitute a powerful metaphor of a parallel world-cyberspace-that can make us forgetful of the concrete material reality that is the grounds for our existence. Indeed, forgetful of the hydrocarbons we are still burning, the materials we are still mining and forgetful of the distant factories producing the objects we are consuming in ever-greater quantities.

As the industrial revolution rolls inexorably on, it has been shadowed by another revolution that represents a yet greater epochal change in the human condition; this is the long-term legacy of the hydrocarbon age and the immediate product of our own way of life. As we push harder against the limits of the Earth to supply materials and energy and to absorb the by-products of industrial activity, a growing environmental crisis that is truly the flip-side of cyberspace casts a lengthening shadow over our technological cornucopia. Rooted firmly in physicality and the limits of concrete and contingent materiality, this new epoch must produce a revolution in human life, for better or worse, or destroy our civilisation. This, the current epoch, has been dubbed by the atmospheric chemist Paul Crutzen the Anthropocine, with a suggested beginning date coinciding with James Watt's invention of the improved steam engine in the late eighteenth century. Crutzen argues that by virtue of our increasing population coupled with increasing exploitation of natural resources, humanity now represents a force of nature with a significant, non-localised, impact on global natural systems and that this must be acknowledged if our civilisation is to survive (Lewis, S., 2009, p. 32).

To understand the potential role of the crafts in negotiating our way out of hyperindustrialism and turbo-capitalism, it is useful to look back to the intellectual foundations of the Arts and Crafts Movement. Rather than focus on the Movement's aesthetic contribution in the history of design or art, it can be more usefully reframed as a social and political movement that attempted to address the question of what constitutes the 'good life'. The 'good life' here refers to a philosophical tradition that, in the West, dates back to classical Greece. It is concerned with an ethical life that is at once fulfilling and lived in a manner consistent with one's values, as distinct from a life of material abundance or one that is free from fear or effort. The Arts and Crafts Movement sought to address this question under the conditions imposed by industrialisation and, more importantly, sought to examine the potential opened up by new technologies and the challenge they presented to the existing social and political order. Importantly, it put objects and their production at the very centre of these efforts.

Within the diversity of practices and beliefs that come under the rubric of 'Arts and Crafts' there is an implicit unifying theme. This is an alternative form of individuation or 'selfhood' to the atomistic conception of the individual characteristic of Modernism. This can be characterised as, in a broad philosophical sense, ecological because it emphasises relational identity and 
interdependency over a sharp distinction between subjects, or indeed between subjects and objects. This alternative worldview operates on several levels and embraces both the production of objects, which was considered as the foundation of our relationship with nature and with one another, and natural and social context of this production. For the present purposes, this intellectual thread will be followed through ideas of three key individuals in the history of the Arts and Crafts: John Ruskin (1819-1900), William Morris (1834-1896) and Charles Robert Ashbee (1863-1942).

Though he provocatively described himself a 'Tory of the old school', Ruskin's thought offers a truly radical critique of some of the central values of Western civilisation. In his lifetime The Nature of Gothic, a chapter from the Seven Lamps of Architecture (1849), became his best-known work. It was considered so significant that William Morris described it as 'one of the very few necessary and inevitable utterances of the century' and his Kelmscott Press published it as a separate volume in 1892. If any one of Ruskin's works were to deserve a similar accolade today, I believe it would be a lecture curiously titled The Work of Iron that he delivered at Tunbridge Wells, in the English county of Kent in 1858 (Ruskin, 1904, pp. 337-8).

In the midst of an industrial revolution largely built upon iron, Ruskin asked his audience to reconsider the true work of iron in the world. Here he sets about overturning the contemporary understanding of this most common metal by arguing that its greatest value is to be found in its rusted form, where it has undergone a 'vital change', combining with oxygen to become '.......sand, lime, clay, and all the rest of the earths' that sustain plant and animal life and, ultimately, human civilisation. Here in '...permanent unity with the purest air which he himself breathes...' iron is most truly useful to man. Ruskin presents a graphic and prescient vision of the inevitable outcome of a contemporary Victorian instrumentalism that could only value iron as a 'resource':

"...but how would you like the world, if all your meadows, instead of grass, grew nothing but iron wire - if your arable ground, instead of being made of sand and clay, were suddenly turned into flat surfaces of steel - if the whole earth, instead of its green and glowing sphere, rich with forest and flower, showed nothing but the image of the vast furnace of a ghastly engine - a globe of black lifeless excoriated metal?" (Ruskin 1904, Vol. 16, p.337)

Ruskin extends his image of a world unified by the vital combination of elements rather than their separation, by asking:

"Is it not strange to find this stern and strong metal mingled so delicately in our human life that we cannot even blush without its help?" (Ruskin, 1904, Vol. 16, p. 384)

In addressing the role of iron in 'art' he uses the metaphorical image of that most typical of Victorian artefacts, the cast iron fence. Remembering that such fences were a relative novelty in the mid-nineteenth century, he contrasts a 
world divided by iron fences where the people are likely to be "sophisticated, unkind, uncomfortable and unprincipled" with one free of them, in which the population will be found to be "for the most part, simple, happy, benevolent and honest". Ruskin is making two points here. He uses iron as a metaphorical thread to unify a discussion that spans issues customarily treated within discrete disciplines such as geology, human physiology, chemistry and political economy and demonstrates the interrelatedness of all phenomena. The iron fence is his metaphor for all human artifice, by embedding it in its social context Ruskin emphasises its non-neutrality. Ruskin revisits the fence theme in a later publication, The Crown of Wild Olive: ThreeLectures on Work, Traffic and War (1866). Here he discusses observations made during a walk through then village of Croydon. He notes that the Carshalton pools near the village have been polluted by:

"heaps of dust and slime, and broken shreds of old metal, and rags of putrid clothes; which having neither the energy to cart away, nor decency enough to dig into the ground, they thus shed into the stream, to diffuse what venom of it will float and melt, far away, in all the places where God meant these waters to bring joy and health." (Ruskin, 1904 Vol. 18, pp. 387-390)

These, he argues, could be easily repaired: "...half a dozen men, with one day's work could cleanse those pools and trim the flowers about their banks".

In a parallel observation Ruskin notes that a new public house in the village has a fence enclosing a narrow strip of land between the building and the footpath that consists of "as much iron and iron work, indeed, as could well be put into the space". This he describes as nothing other than a useless "receptacle for rubbish' and asks "how did it come to pass that this work was done instead of the other; that the strength and life of the English operative were spent defiling the ground instead of redeeming it?" The fence represents a triple evil as "... work, partly cramped and perilous, in the mine"; work "partly grievous and horrible at the furnace" and, finally, as work "partly foolish and sedentary, of ill taught students making bad designs" (Ruskin, 1904, pp. 387-390). His point is, of course, that all of this production is to make money without regard to the larger picture. Here Ruskin's inevitably unsuccessful coinage "illth", or what is now referred to, almost equally uncomfortably, as 'discommodity' is contrasted with the genuine life affirming wealth that would arise from a culture of care that nurtured both the land and its people.

William Morris as both a crafts practitioner and a social activist was deeply influenced by Ruskin's thought. In his essay How we Live and How we Might Live, he succinctly outlines his requirements for a decent life:

"First a healthy body; second, an active mind in sympathy with the past, the present and the future; thirdly, occupation fit for a healthy body and an active mind; and fourthly a beautiful world to live in." (Morris, 1910-25, p. 25) 
In his emphasis on occupation that nurtures both the mind and the body combined with a beautiful environment, Morris's debt to Ruskin is clear. Morris put the production of objects at the centre of his political and aesthetic theory, arguing that this determines, to a great extent how we are to live. Considering the broader, global, impacts of capitalism on peoples outside Britain, he wrote:

" ...the goods are forced on him by their cheapness, and with them a certain kind of life which that energetic, that aggressive cheapness determines for him: for so far reaching is this curse of commercial war that no country is safe from its ravages; the traditions of a thousand years fall before it in a month; it overruns a weak or semi-barbarous country, and what ever romance or pleasure or art existed there, is trodden down into a mire of sordidness and ugliness; the Indian or Javanese craftsman may no longer ply his craft, leisurely working a few hours a day, in producing a maze of strange beauty on a piece of cloth: a steam engine is set a going at Manchester and that victory over nature and a thousand stubborn difficulties is used for the base work of producing a sort of plaster and shoddy, and the Asiatic worker, if he is not starved to death outright, as plentifully happens, is driven himself into a factory to lower the wage of his Manchester brother worker. ...the South Sea islander must leave his canoe carving, and his graceful dances, and become the slave of a slave." (Morris, M., pp. 8-9)

He is equally critical of the consumption side of the equation arguing against the limitations imposed by industrial capitalism and its homogenising effects:
“... the market assumes certain wares are wanted; it produces such wares, indeed, but their kind and quality are only adapted to the needs of the public in a very rough fashion, because the public needs are subordinated to the interests of the capitalist masters of the market, and they can force the public to put up with the less desirable article if they choose, as they generally do. The result is that in this direction our boasted individuality is a sham; and persons who wish for anything that deviates ever so little from the beaten path have either to wear away their lives in a wearisome and mostly futile contest with a stupendous organization which disregards their wishes, or to allow those wishes to be crushed out for the sake of a quite life." (Morris, p. 333)

Tellingly for us in this era of cyberspace and Second Life and in an era of British technological, economic and military supremacy, Morris criticised life in his contemporary industrial civilisation as enervating; arguing that "vicarious life is the watchword of our civilisation ..." (Morris, p.338)

CR Ashbee founded the Guild of Handicraft in 1888, originally locating it in a poor, working class area in East London. In 1902 it was moved to the Cotswold village of Chipping Campden. The Guild was perhaps the boldest attempt to realise the ideals of the Arts and Crafts Movement in practice, intimately uniting life and work in a utopian rural setting. Ashbee was deeply influenced by Ruskin's philosophy of art and Morris's socialism. Additionally, he was influenced by the writings of the social anthropologist Edward Carpenter (1844-1929) and his theory of homogenic love. This was based in Lamarckian evolutionary 
theory, which predated the mechanism of evolution through natural selection proposed by Charles Darwin. Jean Baptiste Lamarck (1744-1829) argued that individual organisms physically changed in direct response to their environment to produce useful adaptations and that these are passed on directly to their offspring. Additionally, Carpenter believed that human beings were motivated, above all, by love of the human form. This love, he argued, led to the progressive perfection of that form itself and would eventually lead to the elimination of the physical and mental flaws that produce human greed and hatred.

For Carpenter and Ashbee, homogenic love, which was a comradely love between members of the same sex that might or might not involve sexual intimacy, was a higher form of relationship that was not confused by the property and reproduction agendas of the socially sanctioned heterosexual marriage relationship (Eisenman, S.,\& Granof, C., 2008, pp. 52-4). The Guild's move to the countryside was intended to move its members from the degrading influences of the city to an environment in which the human will toward homogenic love would be freed to produce greater perfection through the process of Lamarckian evolution. Importantly, this move to the country did not entail a rejection of technology. For Ashbee, technology was a sign of dynamism and progress; it was evidence of human progress through evolution and adaptation. For him, however, this did not mean that human beings should adapt to market capitalism: rather, he argued that the worker and the machine should adapt to one another. In practical terms this meant that while the Guild members used machines, there was no division of labour and all finishing and decorative work was done by hand (Eisenman, S. and Granof, C, 2008, p. 56). The work and the worker's freedom of expression were integral to Ashbee's belief that under the right conditions humanity would evolve toward harmonious perfection. Ashbee believed that the utopian conditions established at Chipping Campden would radiate from there, in a manner analogous to Lamarkian biological evolution, and to slowly transform British society.

Economic factors made the Chipping Campden experiment increasingly difficult to sustain and the Guild was wound up in 1921. Tellingly, Fiona MacCarthy attributes the Guild's decline partially to competition both from manufacturers such as Liberty and Co whose products imitated the handmade look of the Guildsmen's work, and partially to middle class amateurs and hobbyists undercutting the Guild's prices (MacCarthy, 1981., pp. 74, 173 \& 180). The distance that the Guild had put between itself and its customers was also a major contributor to its demise. Although the theory of homogenic love has limited interest to contemporary thought and despite the fact that Ashbee's theories at times drifted uncomfortably close to racism, it does illustrate how deeply Ashbee was motivated by a concern for how we are to live, for the good life. It is also important because Ashbee was able, more than any other theorist of the nineteenth century craft movement, to put his ideas into practice; he attempted to provide a meaningful life for the Guild's members that had work, the production of beautiful things and comradeship at its centre. While an admirably bold attempt to create a pocket of utopia in an ugly world, the Guild 
of Handicraft experiment, also points directly to the futility of either confronting capitalism head-on or of attempting to escape from its pervasive influence to another place.

Raymond Williams has argued that in history sensibilities change slowly, overlapping considerably as they do so: one slowly emerging into dominance as another slowly sinks (Williams, R. 1977, pp. 121-126). John Ruskin's thought was influenced by the comparatively new sciences of biology and geology: both of which stand in contrast to the mechanical sciences that rose to dominance during the Enlightenment in the eighteenth century. While the latter emphasised abstraction and mathematical uniformity through universally acting laws of nature, the younger sciences emphasised complex interactive processes within historically determined, particular and concrete environmental contexts. It is possible that we are witnessing the quickening of a slow change in sensibility that was, in some senses, prefigured by Ruskin and the Arts and Crafts Movement. It is possible that contemporary manifestations of this epochal change in sensibility, stimulated by the accelerating environmental damage and social alienation, can be seen in contemporary developments such as the Slow Movement, bioregionalism, a growing concern for cultural heritage preservation, the valuing of resources promoted by recycling and reuse and, most recently, the notion of 'emotionally durable' design.

What these movements share is an emphasis on the historically determined particular that leads to craft approaches to lifestyle and the production of goods. This distinguishes them from the paradigm of industrial mass-production in which processes are designed to facilitate high-volume production by eliminating the kinds of particularity that requires care and attention. This can be exemplified by the manufacture of wood-based sheet materials. The manufacture of these requires that wood-a material with distinct and individual characteristics such as grain, colour and density - is ground up into pieces sufficiently small that for all intents and purposes they lose these characteristics and are recombined with the addition of glue to produce a material that is uniform and unvarying. In contrast, the working of sawn timber requires attention to the individual characteristics of each board.

Bioregionalism is an approach to sustainability that emphasises the local production of goods-food and energy in particular-within geographical limits determined by ecological and cultural considerations. Such an approach requires a deep familiarity with place: the sustainability of resources within that place requires practices that are carefully crafted to its particulars. The Slow Food movement is really a subset of bioregionalism that began in Italy as a reaction to fast food. Drawing upon traditional, regional cuisine its practitioners celebrate limits. What they eat is contingent upon what can be grown in a particular place and is available in a particular season. Slow food is, of course, an altogether different proposition in settler cultures such as Australia. Here, we cannot draw upon tradition but must invent, craft indeed, new regional cuisines adapted to the climate and geography of particular places. 
The preservation of cultural heritage entails a respect for what is and a preparedness to work with and around it. Unlike 'greenfield' sites, the reuse of existing buildings and places requires gentle and considerate interventions that are essentially craft- based. This extends to all forms of reuse in which objects, often originally mass- produced, have been rendered unique and individual through their post-production trajectories and geographic dispersal (in contrast, recycling erases this history by reducing objects to raw materials, often reconcentrating them for the production of new objects). Effective reuse of redundant objects cannot be achieved through mass-production and requires an imaginative, craft oriented engagement with the things themselves. Emotionally Durable Design is an approach that seeks to prevent redundancy not through mere physical durability that has proven ineffective, but by designing objects whose lives are prolonged because people become emotionally attached to them. Craft, with its inbuilt material, process and personal narratives and unique objects has a powerful resonance with this concept.

It has been argued that the environmental problems assailing humanity should be addressed through a business-as-usual approach and the effects of unintended by- products ameliorated by technological fixes such as geo-engineering. At the other end of the spectrum, there are proposals for radical de-industrialisation and a 'return' to an agrarian or even subsistence lifestyle. Ignoring the catastrophic implications of failure, the combined difficulties of achieving global consensus on geo-engineering and the likely uneven distribution of its benefits if unilaterally deployed, make it an unpromising solution. Entailing as it does an implicit radical reduction in human populations, the return to the land ethos is equally fraught. A simple business as usual approach, however, is likely to produce both effects; an unwitting and uncontrolled re-engineering of the global weather system and a radical, involuntary, reduction of the population.

It would seem that the question addressed by Ruskin, Morris and Ashbee, the question of how we are to live and what constitutes the good life remains central to a sustainable future. It has been argued that compact, well-designed cities provide the best opportunities to reduce our collective and individual carbon footprints and hence our impact on the global environment. Such cities could enable us to reduce our impact on the countryside and wilderness while maintaining the cosmopolitan individualism that is now one of the most cherished values of our culture. This emergent urban sensibility is evident in movements such as guerrilla gardening and indi-craft. These movements are decentred and non-utopian, crafting things and places-and thereby lives - from the what-already-is rather than an imagined what- should-be. All of these movements share a rejection of the abstract idealism characteristic of modernism, embracing instead the local and the concrete in all of its historically determined particularity. It is here in the work of imagining a humane, environmentally sustainable future for our civilisation that the Crafts, drawing upon the historical legacy of its nineteenth century founders, should look to find their relevance to the twenty first century. 


\section{Bibliography}

Chapman, J., 2005, Emotionally durable design: objects, experiences and empathy. London: Earthscan Books

Eisenman, S. and Granof, C., eds., 2008, Design in the Age of Darwin: from William Morris to Frank Lloyd Wright, Northwestern University, Mary and Leigh Block Museum of Art

Lewis, S., 2009, A force of nature: our influential Anthropocene period. London: The Guardian, UK MacCarthy, F., 1981, The simple life. Berkeley and Los Angeles: University of California Press Morris, M. ed., 1910-15, The Collected Works of William Morris, London: Longmans, Green

Ruskin, J., 1904, The complete works of John Ruskin: library edition. Cook, E. T., and Wedderburn, A., eds., London: George Allen Publishers

Sudjic, D., 2008, The language of things. London: Penguin Books

Williams, R., 1977. Marxism and Literature, Oxford: Oxford University Press 